\title{
Lead levels in domestic water supplies and neural tube defects in Glasgow
}

Paediatric Specialist Registrar, Royal Hospital for Sick Children, Community Child Health, 10 Chalmer's Crescent, Edinburgh EH9 1TS, UK

J E Macdonell

Senior Lecturer, Public Health Sciences, The Universtiy of Edinburgh, Medical School, Teviot Place, Edinburgh EH9 9AG, UK

H Campbell

Director, Paediatric Epidemiology and Community Health (PEACH) Unit, Royal Hospital for Sick Children, Yorkhill, Glasgow G3 8SJ, UK D H Stone

Correspondence to: Dr Macdonell

Accepted 14 September 1999

\author{
J E Macdonell, H Campbell, D H Stone
}

\begin{abstract}
Objective-To study the association between "pregnancy" prevalence (affected births and terminations) of neural tube defects in postcode districts of Glasgow and lead concentrations in domestic water.

Setting-Postcode districts of Glasgow supplied by water from the Loch Katrine reservoir.

Design-An ecological study. Lead concentrations from 1911 randomly selected domestic water samples were obtained from the Glasgow 93 lead study. Neural tube defects (affected births and terminations) were identified from the Glasgow register of congenital anomalies for the period 1983-95 for each postcode district in the study population. Correlations were sought between lead concentrations and pregnancy prevalence of neural tube defects/1000 live births in postcode districts.
\end{abstract}

Results-No correlation was found between domestic water lead concentrations $>10 \mu \mathrm{g} / \mathrm{litre}$ and pregnancy prevalence of neural tube defects within postcode districts. Areas of Glasgow previously with high domestic water lead concentrations did not have a higher prevalence of neural tube defects. Houses with the lowest domestic water lead concentrations were in Carstairs deprivation categories 1 (least deprived), 6, and 7 (most deprived). The highest pregnancy prevalence of neural tube defects was found in the most deprived areas.

Conclusion-Deprivation is a risk factor for neural tube defects and might have been a confounding factor in previous studies looking at the association between such defects and domestic water lead concentrations. This study does not support the hypothesis that levels of lead $>10 \mu \mathrm{g} /$ litre in domestic water supplies are associated with a higher pregnancy prevalence of neural tube defects. The reasons behind the decline in pregnancy prevalence of neural tube defects seen in the past two decades remain unexplained. (Arch Dis Child 2000;82:50-53)

Keywords: neural tube defects; lead; folic acid

Penrose was the first to speculate that the wide regional variations in the prevalence of anencephaly might be the result of differences in the local water supply. ${ }^{1}$ Subsequent studies testing the hypothesis that differences in amounts of trace elements in the water supplies in different areas could contribute to different prevalence rates of neural tube defects have not provided consistent evidence, although there has been a tendency towards a higher prevalence in hard water areas. $^{2-6} \mathrm{~A}$ matched case control study investigating lead concentrations in domestic water supplies concluded that lead could be a contributing factor to neural tube defects, particularly for anencephaly. ${ }^{7}$

Over the past two decades in Glasgow there has been a dramatic decline in the pregnancy prevalence of neural tube defects, ${ }^{8}$ and this has occurred at the same time as a reduction in the plumbosolvency of Glasgow's domestic water supplies. The existence of the large Glasgow 93 lead study gave the opportunity to investigate whether there was any correlation between domestic water lead concentrations and the pregnancy prevalence of neural tube defects in Glasgow.

\section{Methods}

The target population of the Glasgow 93 lead study comprised women who had given birth to a live child between October 1991 and September 1992 and who received their domestic water supply from Loch Katrine. The sampling strategy aimed to identify a representative sample of the target population, and to identify adequate numbers of householders with water lead concentrations in the ranges $<2,2-9,10-24$, $25-49$, and $>50 \mu \mathrm{g} /$ litre. All mothers living in four areas known to have had relatively high amounts of lead in water in the past (Pollokshields, Newlands, Cardonald and Hillhead $)^{9}$ were contacted, together with a $30 \%$ random sample of mothers from the remainder of the target area. All the mothers were sent a postal questionnaire and invited to return a water sample from their kettle. Response rates were $56 \%$ from Pollokshields, Newlands, Cardonald, and Hillhead and $40 \%$ from the other areas. Tap water lead measurements from 1911 households were obtained. A sample of 342 mothers also had blood lead concentrations measured, which showed a direct relation with their tapwater lead concentrations. ${ }^{10}$ For our study, the data for the 1911 tap water lead samples were provided by Professor GD Murray who was involved in the Glasgow 93 lead study.

Live birth data by postcode sectors from 1983 to 1995 were obtained from the Greater Glasgow Health Board. Data for neural tube defects were obtained from the Glasgow Register of Congenital Anomalies. From 1983 to 1995 there were 144006 live births and 331 neural tube defects identified in the study population. Data available from each case of 
Table 1 Distribution of lead concentrations in

Lead concentration ( $\mu \mathrm{g} /$ litre) Count <2 953 $2-10$ $10.1-50$

$>50$ 621 298

Data taken from the Glasgow 93 lead study. domestic water

neural tube defect consisted of date of birth, address, and Carstairs deprivation category.

Statistical analysis was carried out using Microsoft Excel. The primary analysis was to investigate whether there was any correlation between water lead concentrations and the pregnancy prevalence of neural tube defects. The pregnancy prevalence of neural tube defects for each 1000 live births was calculated for each postcode sector. Because there were only small numbers of water samples for each postcode sector, they were grouped into larger postcode districts. All postcode districts with less than five water lead measurements were excluded. The distribution of the lead concentrations for each postcode district is positively skewed, with most postcode districts having very low values, so we were unable to calculate means. Therefore, we expressed the number of water lead measurements that were $>10 \mu \mathrm{g} /$ litre (legal limit for water lead proposed by the European Commission (EC)) as a proportion of the total number of values for each postcode district. The proportion of values $>10 \mu \mathrm{g} /$ litre for each postcode district was then correlated with the pregnancy prevalence of neural tube defects for each postcode district.

Because the last alterations to the plumbosolvency of Loch Katrine water had been made in 1989, we considered the most appropriate analysis to be a comparison of the proportion of water lead values $>10 \mu \mathrm{g} /$ litre for each postcode district with the pregnancy birth prevalence of neural tube defects from 1990 to 1995 in each postcode district. However, the number of neural tube defects recorded over this period was fairly small. When the pregnancy prevalence of neural tube defects from 1983 to 1995 was used in the analysis, an assumption had to be made that over that time period, even with alterations to the plumbosolvency of the water and removal of lead piping, the relative content of lead in domestic water among the postcode districts remained the same.

As discussed earlier, there were four areas in Glasgow (Pollokshields, Hillhead, Newlands, and Cardonald) that were known by the water board to have had high concentrations of lead in the past. ${ }^{9}$ Therefore, we also compared the

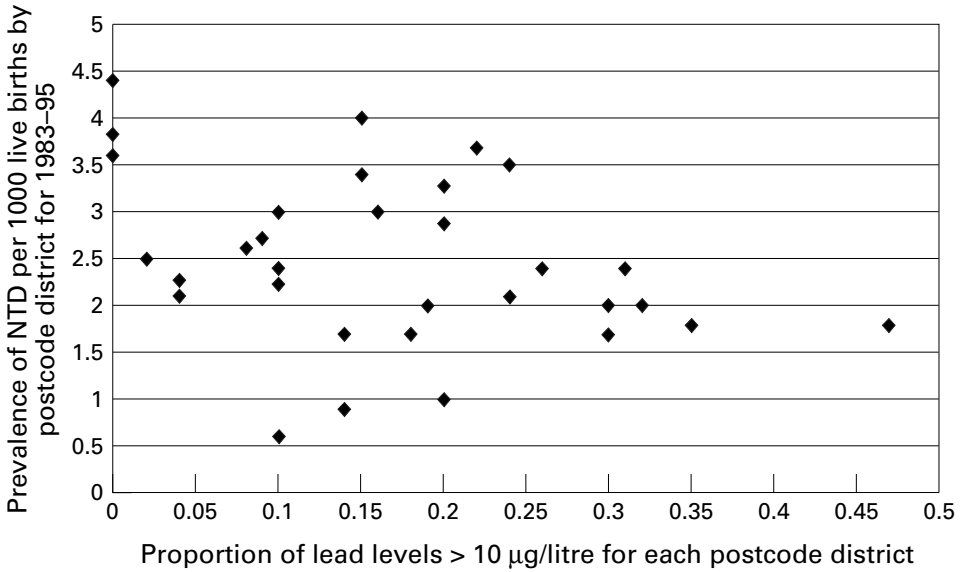

Figure 1 Scatter plot comparing the prevalence of neural tube defects (NTD) with the proportion of lead measurements $>10 \mu \mathrm{g} /$ litre for each postcode district for the period 1983-95. pregnancy prevalence of neural tube defects for each 1000 live births for these four areas combined with that of the pregnancy prevalence of neural tube defects for each 1000 live births for the rest of the study area.

The only confounder for which data were available was area deprivation as measured by the Carstairs deprivation index. For each of the seven Carstairs deprivation categories both the pregnancy prevalence of neural tube defects and the proportion of lead values $>10 \mu \mathrm{g} /$ litre were calculated.

\section{Results}

Table 1 shows the positively skewed distribution of the lead concentrations of the water samples. When the pregnancy prevalence of neural tube defects for each 1000 live births from 1983 to 1995 and the proportions of lead values $>10 \mu \mathrm{g} /$ litre for each postcode district are combined to produce a scatter graph, the points are widely spread (fig 1 ). There is no association between the two variables and this is confirmed by a Pearson correlation coefficient of $r=-0.33$. For the reasons discussed previously, it was more appropriate to perform a scatter graph of pregnancy prevalence figures of neural tube defects for the period 1990-5 against the proportions of lead values $>10 \mu \mathrm{g} /$ litre for each postcode district. This gave a similar result with a Pearson correlation coefficient of $r=-0.16$.

Four areas (Pollokshields, Cardonald, Hillhead, and Newlands) were thought to have had high domestic water lead concentrations in the past. Table 2 shows the pregnancy prevalence of neural tube defects for each 1000 live births in these areas compared with the pregnancy prevalence in the other areas combined. Over the 1983-95 and 1990-5 periods, the pregnancy prevalence of neural tube defects was relatively lower in these four areas compared with that in the combined other areas. The pregnancy prevalence of neural tube defects dropped further in the "high" domestic water lead areas than the other areas in 1990-5. There was no difference in the mean Carstairs deprivation category for the high areas (5.9) compared with the other areas (5.8).

The pregnancy prevalence of neural tube defects (1983-95) for each Carstairs deprivation category shows a clear trend (table 3 ). The highest pregnancy prevalence of neural tube defects is found in the highest deprivation category, with a risk almost double that of the lowest deprivation category. Table 3 also shows that the lowest proportion of samples containing water lead values $>10 \mu \mathrm{g} /$ litre were in Carstairs deprivation categories 1, 6, and 7 .

Table 2 Pregnancy prevalence of neural tube defects for each 1000 live births for "high" water lead concentrations compared with the other areas for the periods 1983-95 and 1990-95

\begin{tabular}{lll}
\hline & $1983-95$ & $1990-95$ \\
\hline Areas thought to have had high & & \\
$\quad$ water lead concentrations & 2.1 & 0.69 \\
All other areas & 2.4 & 1.8 \\
\hline
\end{tabular}


Table 3 The pregnancy prevalence of neural tube defects (NTDs) for each 1000 live births from 1983-95; the proportion of domestic water lead concentrations $>10 \mu g /$ litre according to Carstairs deprivation category

\begin{tabular}{lll}
\hline $\begin{array}{l}\text { Carstairs } \\
\text { deprivation } \\
\text { category }\end{array}$ & $\begin{array}{l}\text { Pregnancy prevalence } \\
\text { NTDs/1000 live births } \\
1983-95\end{array}$ & $\begin{array}{l}\text { Proportion of water with } \\
\text { lead values } \\
>10 \mu g / l(95 \% \text { CI) }\end{array}$ \\
\hline 1 & 1.6 & $0.16(0.11$ to 0.21$)$ \\
2 & 2.2 & $0.28(0.21$ to 0.34$)$ \\
3 & 2.2 & $0.21(0.14$ to 0.28$)$ \\
4 & 2.2 & $0.29(0.24$ to 0.33$)$ \\
5 & 2.5 & $0.26(0.19$ to 0.32$)$ \\
6 & 2.6 & $0.17(0.13$ to 0.21$)$ \\
7 & 2.8 & $0.12(0.09$ to 0.15$)$ \\
\hline
\end{tabular}

CI, confidence interval.

\section{Discussion}

The Glasgow Register of Congenital Anomalies participates in the multinational EUROCAT (European Registration of Congenital Anomalies and Twins) network funded by the EC. From 1980 to 1988 Glasgow reported the highest rate of neural tube defects of all contributing centres (3.4/1000 births), as a result of a combination of high ascertainment and high risk, ${ }^{11}$ and thus is an important area within which to study the epidemiology of this congenital anomaly. The register has been in existence long enough to enable secular trends to be identified. Stone et al showed that in Glasgow over the period 1974-85, the pregnancy prevalence of anencephaly fell by $50 \%$ (from 2.2 to $1.1 / 1000$ ), whereas the birth prevalence fell by $89 \%$ (from 1.9 to $0.2 / 1000$ ); the pregnancy prevalence of spina bifida fell by $38 \%$ (from 3.4 to $2.1 / 1000$ ), whereas the birth prevalence fell by $76 \%$ (from 3.4 to $0.8 / 1000) .{ }^{12}$ The pregnancy prevalence rate produces a number equivalent to the number of affected births that would have occurred had there been no antenatal screening. The declining trend in pregnancy prevalence of neural tube defects is not confined to Glasgow but is recognised throughout the UK. ${ }^{13}$ It had occurred before the introduction of periconceptional folic acid supplementation for primary prevention of neural tube defects.

Risk factors for prenatal exposure to lead involve maternal exposure and body burden of lead. Drinking water is a major source of lead exposure in the general population. ${ }^{14}$ Studies have shown that there is no impairment to lead crossing the placenta and that maternal and fetal blood lead values are similar. ${ }^{1516}$

During the 1960s, extensive water sampling in the Strathclyde region brought an increasing awareness of plumbosolvency. ${ }^{17}$ The Strathclyde water supply has an acidic character because of its weak buffering capacity and low $\mathrm{pH}$, which makes it aggressive to a variety of metals including lead. Exposure to soft, highly plumbosolvent domestic water supplies in Scotland was postulated as the reason for Scotland having the highest mean blood lead concentrations found in the EC screening programme for blood lead. ${ }^{18}$ By 1968, the former water boards had banned the use of lead in household plumbing, and from 1970 Glasgow District Council removed all lead piping leading to the householders' tap, including the supply pipe, during modernisation of council owned houses. ${ }^{17}$ It was known that the plumbosolvency of water could be considerably decreased by increasing the $\mathrm{pH}$ of the water. The initial measure taken to alter the unsatisfactory $\mathrm{pH}$ of the water was that of the addition of lime to water supplies from Loch Katrine in 1978. Studies performed before and after lime dosing treatment showed that blood lead concentrations fell. In 1977, 6\% of mothers tested had blood lead concentrations $>35 \mu \mathrm{g} /$ litre, but in 1980 none fell into this category. ${ }^{19}$ A second programme involving the addition of orthophosphate to provide a further reduction in plumbosolvency was carried out in 1989 .

In 1980, the European Union drinking water directive reduced the maximum admissible concentration for lead in water from 100 to $50 \mu \mathrm{g} /$ litre. The EC has proposed that the legal limit be dropped from 50 to $25 \mu \mathrm{g} /$ litre within the next five years and to $10 \mu \mathrm{g} /$ litre within the next 15 years (S Robertson, personal communication, 1998). The WHO in 1993 suggested a guideline of $10 \mu \mathrm{g} /$ litre for the concentration of lead in water. ${ }^{14}$

The Glasgow 93 lead study, although the largest random sample of domestic water lead values to be performed in Glasgow, was carried out after measures had been taken to reduce plumbosolvency and after many properties had disposed of lead piping. The results showed that most water lead values were $<10 \mu \mathrm{g} /$ litre (well below the current UK legal limit of $50 \mu \mathrm{g} /$ litre). We acknowledge that there was a response rate bias, in that only $56 \%$ of houses from the high lead areas responded and only $40 \%$ from the low lead areas.

Our study failed to confirm the findings of Bound et al, ${ }^{7}$ which suggested a higher risk of a neural tube defect pregnancy in houses with water lead concentrations $>10 \mu \mathrm{g} /$ litre. In their study, the areas with high water lead concentrations tended to be the areas of highest deprivation, so it is possible that the observed association was confounded by some unknown factor related to deprivation.

We used the Carstairs index as an area based measure of deprivation. It is postcode sector linked and is derived from four census variables judged to represent material disadvantage in the population: overcrowding, male unemployment, social class, and car ownership. These variables are combined to create a composite score. ${ }^{20}$ The deprivation score is divided into seven separate categories designed so as to retain the discriminatory features of the distribution of the deprivation score, rather than to ensure equality of numbers between each deprivation category. We found that water lead values were lower in Carstairs deprivation categories 1 (least deprived), 6, and 7 (most deprived), thus not showing a clear association with deprivation. Those in category $1 \mathrm{might}$ have lower amounts of lead because they are better informed about the dangers of lead pipes and/or they are better financially resourced to have lead piping removed from the domestic supply pipe. The lower amounts of lead in domestic water supplies in categories 6 and 7 can be explained by the fact that the housing is either post-1960s (without lead pipes) or the 
council has removed the lead pipes from council owned property.

There are some possible problems in the use of the Carstairs index. First, it is based on assumptions about the variables that best represent material deprivation. Second, areas are not homogenous: populations containing a mixture of deprived and less deprived households are likely to have middle ranking scores. ${ }^{21}$ However, such mixed populations would be more likely to occur in rural areas. Third, the scores from postcode sectors with small populations $(<2000)$ are based on census counts, which are particularly susceptible to random variation. ${ }^{21}$ Lastly, the ecological fallacy is an important potential limitation of area based measures. ${ }^{22}$

We acknowledge that the population of Glasgow has not remained stable over the past 20 years. It has been declining steadily, with a disproportionate decline in children and young adults, as a result of the reducing birth rate and emigration. ${ }^{23}$ There has also been substantial internal migration, much of it of the "moonlighting" variety and therefore difficult to quantify.

The question of confounding factors is complex. Neural tube defects are positively correlated with deprivation (which was taken account of in the study design). There is a strong negative correlation between maternal age and deprivation. ${ }^{24}$ There is also a weak positive correlation between maternal age and the risk of neural tube defect. ${ }^{25}$ Therefore, any confounding as a result of maternal age differences across postcodes would tend to be more than counteracted by deprivation differences occurring in the opposite direction. In other words, the deprivation adjustment is the important one and should be sufficient.

We found that mothers from the most deprived areas had almost twice the risk of a neural tube defect pregnancy than mothers from the least deprived areas. The higher pregnancy prevalence of neural tube defects in the most deprived categories suggests possible exposure to an unspecified teratogen associated with some component of social deprivation. Recent evidence has shown that primary prevention of neural tube defects is possible through the use of periconceptional folic acid supplementation. It might be that the higher pregnancy prevalence can be explained, at least partly, by poorer, folic deficient diets in deprived mothers. However, there is no evidence that there had been any significant rise in dietary folic acid intake in Scotland over the 1980s and early 1990s to explain the decline seen in the prevalence of neural tube defects in Glasgow. ${ }^{26}$ This decline started in the 1970s and antedates the publication of the major folic acid trials and promotion of folic acid supplementation.

Our ecological study was carried out in an area known to have had high rates of neural tube defects and high domestic water lead concentrations. If even a weak association had been found it might then have been appropriate to proceed to a more expensive and time consuming case control study. In our opinion this is not now justifiable. The reasons behind the fall in pregnancy prevalence of neural tube defects in Glasgow (and other areas) since the 1970 s remain unclear. The decline is partly but not wholly secondary to antenatal screening. There is no substantive evidence to suggest that the dietary folic status of women in Scotland has changed over this period. Our study has not provided any evidence that supports a hypothesis that there is an association between neural tube defects and domestic water lead concentrations. The causes of the decline in neural tube defects over this period remain largely unexplained.

The authors acknowledge Professor G D Murray of the Medical Statistics Unit, Public Health Sciences, University of Edinburgh.

1 Penrose LS. Genetics of anencephaly. 7 Ment Defic Res 1957;1:4

2 Lowe TR, Roberts CJ, Lloyd S. Malformations of central nervous system and softness of local water supplies. $B M 7$ $1971 ; \mathrm{ii}: 357-61$.

3 Fielding DW, Smithells RW. Anencephalus and water hardness in south-west Lancashire. Br f Prev Soc Med 1971;25: 217-19.

4 Morton MS, Elwood PC, Abernethy M. Trace elements in water and congenital malformations of the central nervous water and congenital malformations of the

5 St Leger AS, Elwood PC, Morton MS. Neural tube malformations and trace elements in water. $\mathcal{F}$ Epidemiol Commumations and trace elements
nity Health 1980;34:186-7.

6 Bound JP, Harvey PW, Brooks DM, Sayers BMcA. The incidence of anencephalus in the Fylde peninsula 1956-76 and changes in water hardness. $\mathcal{F}$ Epidemiol Community Health 1981;35:102-5.

7 Bound JP, Harvey PW, Francis BJ, Awwad F, Gatrell AC. Involvement of deprivation and environmental lead in neural tube defects: a matched case-control study. Arch Dis Child 1997;76:107-12

8 European Register of Congenital Anomalies Working Group. Surveillance of congenital anomalies in Europe 1980-1995. Report 6, Part 1: text. Brussels: Institute of Hygiene and Epidemiology, 1995.

9 McIntosh L, Robertson S. Strathclyde water services internal report. Glasgow: Strathclyde Regional Council, 1992.

10 Watt GCM, Britton A, Gilmour WH, et al. Is lead in tap water still a public health problem? An observational study in Glasgow. BMF 1996:313:979-81.

11 Stone DH, Dolk H. High reported prevalence of congenital anomalies in a Scottish city. Scott Med f 1994;39:170-2.

12 Stone DH, Smalls MJ, Rosenberg K, Womersley J. Screening for congenital neural tube defects in a high-risk area: an epidemiological perspective. F Epidemiol Community Health 1988;42:271-3.

13 Seller MJ. Risks in spina bifida. Dev Med Child Neurol 1994; 36:1021-5

14 WHO Regional Office for Europe. Lead and health. A pamphlet for local authorities, health and environment. Geneva: WHO, 1995.

15 Moore MR. Prenatal exposure to lead and mental retardation. In: Needleman HL, ed. Health effects of lead at retardation. In: Needleman HL, ed. Health effects

16 Lacey RF, Moore MR, Richards WN. Lead in water, infant diet and blood: the Glasgow duplicate diet study. Sci Total Environ 1985;41:235-7.

17 Richards WN, Britton A, Cochrane A. Reducing plumbosolvency - the effect of added lime on the Loch Katrine supply to Glasgow. Fournal of the Institute of Water Engineers and Scientists 1980;34:315-33.

18 Department of Environment Central Directorate on Environmental Pollution. European Community screening programme for lead-UK results for 1979-80. Pollution Report No 10. London: Department of the Environment, 1981:15.

9 Moore MR, Richards WN, Sherlock JG Successful abare of Scotland. Environ Res 1985;38:67-76.

20 Carstairs V, Morris R. Deprivation: explaining differences in mortality between Scotland and England and Wales. BMF 1989;299:886-9.

21 McLoone P. Carstairs scores for Scottish postcode sectors from the 1991 census. Glasgow: Public Health Research Unit, 1995.

22 Morgenstern $\mathrm{H}$. Uses of ecologic analysis in epidemiologic research. Am f Public Health 1982;72:1336-44.

23 Annual Report of the Director of Public Health. Glasgow: Greater Glasgow Health Board, 1991.

24 Lopez I, Stone D, Gillmore H. Epidemiology of Down's syndrome in a Scottish city. Paediatr Perinat Epidemiol 1995;9:331-40.

25 Leck I. Structural birth defects. In: Pless IB, ed. The epidemiology of childhood disorders. New York: Oxford University Press, 1994:99.

26 Report of a Working Party to the Chief Medical Officer for Scotland. The Scottish diet. Scotland: The Scottish Office, Scottish Home and Health Department, 1993. 